See discussions, stats, and author profiles for this publication at: https://www.researchgate.net/publication/342871346

\title{
Performance of nickel-iron foam (Ni-Fe) cathode in bio-electrochemical system for hydrogen production from effluent of glucose fermentation
}

Article in Materials Science and Engineering B · October 2020 DOI: 10.1016/j.mseb.2020.114613

\section{CITATIONS}

6 authors, including:

Ibdal Satar

Ahmad Dahlan University

13 PUBLICATIONS 41 CITATIONS

SEE PROFILE

P. Wan Ramli Wan Daud

Universiti Kebangsaan Malaysia

496 PUBLICATIONS 9,582 CITATIONS

SEE PROFILE
READS

43

Mimi Hani Abu Bakar

Universiti Kebangsaan Malaysia

22 PUBLICATIONS 111 CITATIONS

SEE PROFILE

Mohd Yasin Nazlina Haiza

Universiti Kebangsaan Malaysia

17 PUBLICATIONS 325 CITATIONS

SEE PROFILE

Some of the authors of this publication are also working on these related projects:

Project PEM and Alkaline Electrolyzer View project

Project Development of Design Advisor Tools for Direct Methanol Fuel Cell View project 


\title{
Performance of nickel-iron foam (Ni-Fe) cathode in bio-electrochemical system for hydrogen production from effluent of glucose fermentation
}

\author{
Ibdal Satar a,b,*, Mimi Hani Abu Bakar ${ }^{\mathrm{a}}$, Wan Ramli Wan Daud ${ }^{\mathrm{a}, \mathrm{c}}$, Nazlina Haiza Mohd Yasin ${ }^{\mathrm{d}}$, \\ Mahendra Rao Somalu ${ }^{\mathrm{b}}$, Byung Hong Kim ${ }^{\mathrm{e}, \mathrm{f}}$ \\ ${ }^{a}$ Fuel Cell Institute, Universiti Kebangsaan Malaysia, 43600, UKM Bangi, Selangor, Malaysia \\ ${ }^{\mathrm{b}}$ Department of Food Technology, Faculty of Industrial Technology, Universitas Ahmad Dahlan (UAD), 55166, Umbulharjo, Yogyakarta, Indonesia \\ ${ }^{\mathrm{c}}$ Department of Chemical and Process Engineering, Faculty of Engineering and Built Environment, Universiti Kebangsaan Malaysia, 43600, UKM Bangi, Selangor, Malaysia \\ ${ }^{\mathrm{d}}$ Department of Biological Sciences and Biotechnology, Faculty of Science and Technology, Universiti Kebangsaan Malaysia, 43600, UKM Bangi, Selangor, Malaysia \\ ${ }^{\mathrm{e}}$ Korean Institute of Science and Technology, 136-791, Republic of Korea \\ ${ }^{\mathrm{f}}$ State Key Laboratory of Urban Water Resource and Environment, Harbin Institute of Technology, Harbin 150090, China
}

\section{A R T I C L E I N F O}

\section{Keywords:}

Nickel-Iron foam

Catalytic properties

Bio-electrochemical system

Hydrogen production

\begin{abstract}
A B S T R A C T
The high cost of Pt-based cathode, and its possibility of being poisoned by the presence of buffer in the electrolyte are two paramount issues in the BES system. The Ni-Fe has become one of the good alternatives because it has excellent catalytic properties, inexpensive, commercially available and low toxicity to microorganisms. In this study, Ni-Fe foam applied as a cathode in dual-chamber BES, while effluent of glucose fermentation as a substrate in the anode side. The characteristic of Ni-Fe surface was analyzed by using field emission scanning electron microscopy. Whereas, the catalytic property of Ni-Fe was evaluated by using linear sweep voltammetry test. The maximum hydrogen production rate and yield obtained were $500 \pm 80 \mathrm{~m}^{3} / \mathrm{m}^{3} / \mathrm{d}$ and $470.2 \pm 11.2 \mathrm{~mL} / \mathrm{g}$ COD, respectively. The results show that the Ni-Fe has comparable performance to GF/Pt. Hence it could be used as an alternative cathode in BES application.
\end{abstract}

\section{Introduction}

Bio-electrochemical system (BES) is an exciting technology and a potential future approach for hydrogen production owing to its green technology, low cost and technically feasible. Originally, BES was developed for the wastewater treatment and electricity generation using electroactive bacteria (EAB) to facilitate electron transfer from or to the solid electrode. Currently, the research has broadened the utility of BESs to more complex processes such as chemical synthesis, bioremediation and biogas productions [1]. BESs have been able to produce hydrogen as a value-added product from nutrient-rich wastewater with a small additional power supply [2]. As such, BES prospects as an alternative approach to generating hydrogen from the organic substrate $[3,4]$.

BES is a bioreactor technology that is constructed by two compartments, which are the anode and cathode parts. An anode compartment is a place where EAB generates electrons and protons. These electrons and protons transferred to produce hydrogen at the cathode side are then (Eq. (1)). However, BESs require less electrical power to overcome the thermodynamic barrier [1]. Based on the free energy Gibbs calculation, hydrogen production from an organic substrate (i.e., acetate) requires additional energy of $104 \mathrm{~kJ} / \mathrm{mol}$ under standard conditions $[5,6]$. In general, a power source within the range of 0.2 to $0.8 \mathrm{~V}$ is needed to supply the required additional energy for the effective BESs system $[7,8]$.

$\mathrm{CH}_{3} \mathrm{COO}^{-}+4 \mathrm{H}_{2} \mathrm{O} \rightarrow 2 \mathrm{HCO}_{3}^{-}+\mathrm{H}^{+}+4 \mathrm{H}_{2}$

Although BESs is a promising technology in the future, there are still several challenges to overcome for industrial application. The crucial issue in BESs is the cost of cathode development and its environmental impact. Approximately $47 \%$ of the total BES cost is due to the cathode [9]. Most of the research reports the use of expensive metal such as platinum (Pt) as the primary cathode material [10]. Due to the high cost and its reaction with the buffer solution which end up being poisonous, the alternative materials to replace this Pt-based material has become inevitable. Several metal materials were actively studied such as stainless steel (SS), cobalt (Co), nickel alloy [11-13], Ni mesh (NM) [14] and nickel foam (NF) [15], to reduce BESs cost as a whole. Among

\footnotetext{
* Corresponding author at: Department of Food Technology, Faculty of Industrial Technology, Universitas Ahmad Dahlan (UAD), 55166, Umbulharjo, Yogyakarta, Indonesia.

E-mail address: ibdalsatar@yahoo.com (I. Satar).
} 
these materials, nickel is the most significant material to replace Pt owing to its excellent catalytic properties for hydrogen evolution reaction (HER)[16].

In addition to the cathode materials, investigation on the organic substrate in the anode side is necessary to represent the BES performance in a real application. In this study, the effluent of glucose fermentation (EGF) with a small modification $(\mathrm{pH}=7.0)$ became the substrate to generate hydrogen. In anaerobic condition, glucose can be fermented by mixed culture to generate volatile fatty acids (VFAs) in addition to biogas and/or alcohols as shown in Eq. (2) and (3). Several studies showed that the acetic acid are one of the main VFAs in the EGF $[17,18]$. Therefore, we assumed that EGF can be reused as a substrate. Besides, EGF can also represent the real wastewater model to generate hydrogen in the BES system.

$$
\begin{aligned}
& \mathrm{C}_{6} \mathrm{H}_{12} \mathrm{O}_{6}+2 \mathrm{H}_{2} \mathrm{O} \rightarrow 2 \mathrm{CH}_{3} \mathrm{COOH}+2 \mathrm{CO}_{2}+4 \mathrm{H}_{2} \\
& \mathrm{C}_{6} \mathrm{H}_{12} \mathrm{O}_{6} \rightarrow 2 \mathrm{CH}_{3} \mathrm{CH}_{2} \mathrm{OH}+2 \mathrm{CO}_{2}
\end{aligned}
$$

Though nickel has been successfully disclosed by other researchers to replace Pt, the research on nickel-iron (Ni-Fe) performance in the BESs system is still limited, especially its efficiency for hydrogen production from EGF. The current research using NM [14], NF [15] and nickel-iron-zinc (NiFeZn) [19] have been reported only by several researchers. Based on a report by Salembo et al. [11], the presence of Fe in $\mathrm{Ni}$ alloy exhibited a catalytic activity of the cathode. Besides, the performance of bimetallic catalysts is generally better than monometallic catalysts. This difference in performance is due to the synergetic effect between those two metals, which may combine the properties related to the two individual metals, hence generate new and distinctive properties [20]. Consequently, the bimetallic Ni-Fe foam becomes a good option compared to the monometallic $\mathrm{Ni}$ foam. Therefore, this study embarks the objective to investigate the potential of $\mathrm{Ni}-\mathrm{Fe}$ as a new alternative cathode in the BES system to produce hydrogen. In addition to the use of BES systems equipped with Ni-Fe cathode, also, the EGF as a real wastewater model will be used as substrate in this study.

\section{Materials and methods}

\subsection{Electrode preparation}

Graphite felt (GF), and Ni-Fe foam were purchased from Sigma Aldrich Malaysia Sdn. Bhd. GF and Ni-Fe were initially prepared with a size of $5.0 \mathrm{~mm} \times 5.0 \mathrm{~mm}$. In this study, an acid $(\mathrm{HCl})$ and base $(\mathrm{NaOH})$ treatments were performed to remove impurities on the material surfaces. Both GF and Ni-Fe were immersed in $1 \mathrm{M} \mathrm{HCl}$ and then in $1 \mathrm{M}$ $\mathrm{NaOH}$ for $1 \mathrm{~h}$. Each step was followed by washing with deionized water (DW) thrice $[7,21,22]$. Next, GF and Ni-Fe were dried overnight in the oven at $80{ }^{\circ} \mathrm{C}$. Before applied in BES system, the treated GF and Ni-Fe materials were characterized by using an energy dispersive X-ray method (EDX, Incorporated Inca, Point \& Analyses Software) [23] to determine the elemental compositions on the surfaces. The elemental compositions on the GF and Ni-Fe surfaces after acid and base treatments (at startup) are listed in Table 1.

As a comparison, platinum catalyzed graphite felt (GF/Pt) was used as a control in the cathode side in this work. GF/Pt cathode was prepared as described by Satar et al. [22] in which a $0.05 \mathrm{mg} / \mathrm{cm}^{2} \mathrm{Pt}$ was coated on the GF surface using Nafion solution as a binder. GF/Pt is the most common cathode used in BES systems, and the cost for this material is relatively cheap compared to the Pt sheet.

\subsection{Electrolyte preparations}

The EGF was collected from a previous study [18]. Volatile fatty acids (VFAs) were characterized using high-performance liquid chromatography (HPLC) equipped with a UV detector at $220 \mathrm{~nm}$ (HPLC-UV,
Table 1

Elemental compositions of electrode materials from EDX analysis at startup and

\begin{tabular}{|c|c|c|c|c|c|c|}
\hline \multirow[t]{2}{*}{ Electrodes } & \multicolumn{6}{|c|}{ Element compositions (\%) } \\
\hline & C & $\mathrm{Ni}$ & $\mathrm{Fe}$ & $\mathrm{o}$ & Pt & Others* \\
\hline \multicolumn{7}{|l|}{ Startup } \\
\hline GF & 100.0 & ND & ND & ND & ND & ND \\
\hline $\mathrm{GF} / \mathrm{Pt}^{* * *}$ & 92.1 & ND & ND & 3.7 & 1.2 & 3.0 \\
\hline $\mathrm{Ni}-\mathrm{Fe}$ & ND & 99.4 & 0.6 & ND & ND & ND \\
\hline \multicolumn{7}{|c|}{ After six months of BES run } \\
\hline GF & 70.1 & ND & ND & 15.7 & ND & 14.2 \\
\hline $\mathrm{GF} / \mathrm{Pt}$ & 72.1 & ND & ND & 12.3 & 0.2 & 15.4 \\
\hline $\mathrm{Ni}-\mathrm{Fe}$ & ND & 12.2 & ND & 37.5 & ND & 50.3 \\
\hline
\end{tabular}
after six months of BES operations.

$\mathrm{ND}=$ not detected; * = K, Na, Mg, Cl, P; ** = GF after coated with Pt (GF/Pt)

Table 2

Composition of volatile fatty acids in EGF sample.

\begin{tabular}{llll}
\hline VFA composition & Retention time (min) & $(\mathrm{mg} / \mathrm{L})$ & $\%(\mathrm{v} / \mathrm{v})$ \\
\hline Malic & $1.79 \pm 0.01$ & $124.78 \pm 0.05$ & $7.75 \pm 0.01$ \\
Succinic & $2.61 \pm 0.01$ & $11.13 \pm 0.06$ & $0.71 \pm 0.01$ \\
Lactic & $3.26 \pm 0.01$ & $345.83 \pm 0.09$ & $34.59 \pm 0.01$ \\
Acetic & $3.99 \pm 0.01$ & $556.23 \pm 0.15$ & $52.97 \pm 0.01$ \\
Propionic & $5.18 \pm 0.02$ & $2.91 \pm 0.02$ & $0.30 \pm 0.02$ \\
Butyric & $6.78 \pm 0.02$ & $35.45 \pm 0.15$ & $3.68 \pm 0.02$ \\
\hline
\end{tabular}

HPLC 1100 s Agilent, USA). The mobile phase was a mixture of 5\% acetonitrile and $95 \% 2 \mathrm{mM}$ sulphuric acid with a flow rate of $0.6 \mathrm{~mL} /$ min, oven temperature of $40{ }^{\circ} \mathrm{C}$. The stationary phase was a GRACE Genesis C-8 $4 \mathrm{u}$ column $(150 \mathrm{~mm} \times 4 \mathrm{~mm})$ [24]. The VFAs compositions and HPLC chromatogram are presented in Table 2 and Fig. 1, respectively. EGF was filtered by using a filter paper (Whatman, $150 \mathrm{~mm} \Theta$ Cat No 1001-150) to remove its solid materials. The EGF was adjusted to $\mathrm{pH}$ values of 7.0 using $2 \mathrm{M} \mathrm{Na}_{2} \mathrm{HPO}_{4}$ to ensure the activity of electroactive bacteria at the anode compartment [25]. Then, the filtrate was used as the carbon source (anolyte) for hydrogen production in the anode chamber of the BES system. Potassium chloride (KCl) with $0.1 \mathrm{M}$ at $\mathrm{pH}=7.0$ was used as catholyte to facilitate the electron and proton flow at the cathode.

\subsection{GF, GF/Pt and Ni-Fe surface Analyses}

GF, GF/Pt and Ni-Fe surfaces were characterized by using field emission scanning electron microscopy (FESEM, JEOL JSM 5800) to investigate the morphology of material surfaces at the startup and after six months of BES operation. The FESEM was operated at an accelerated voltage of $20 \mathrm{kV}$ and a distance of $10 \mathrm{~mm}$ for material imaging in different sections. The images were captured by using a high resolution of $1280 \times 960$ and a dwell time of 160 s. Meanwhile, the elemental compositions were determined by using the electron dispersive X-ray (EDX) method (Incorporated Inca, Point \& Analyses Software) [23].

\subsection{Bioreactor Set-up}

An acrylic block with a volume of $25 \mathrm{~mL}$ $(50 \mathrm{~mm} \times 10 \mathrm{~mm} \times 50 \mathrm{~mm}$ ) for each anode and cathode compartments of BES were used in this study. The anode and cathode compartments were separated with cation exchange membrane (CEM, CMI $7000 \mathrm{~s}$ ) with an active surface area of $25 \mathrm{~cm}^{2}$. Before CEM applied into the BES, it was initially treated with $5 \%$ sodium chloride $(\mathrm{NaCl}$, $\mathrm{pH}=7.0$ ) overnight to activate the ion membrane permeability [26]. GF and Ni-Fe were used as anode and cathode material, respectively. The electrodes were then connected with titanium wire to facilitate electron transfer via an external circuit. The reference electrode of $\mathrm{Ag}$ / $\mathrm{AgCl}(+0.197 \mathrm{~V}$ vs SHE) was applied either at the anode or cathode chamber. Subsequently, the BES was operated in batch mode with a 


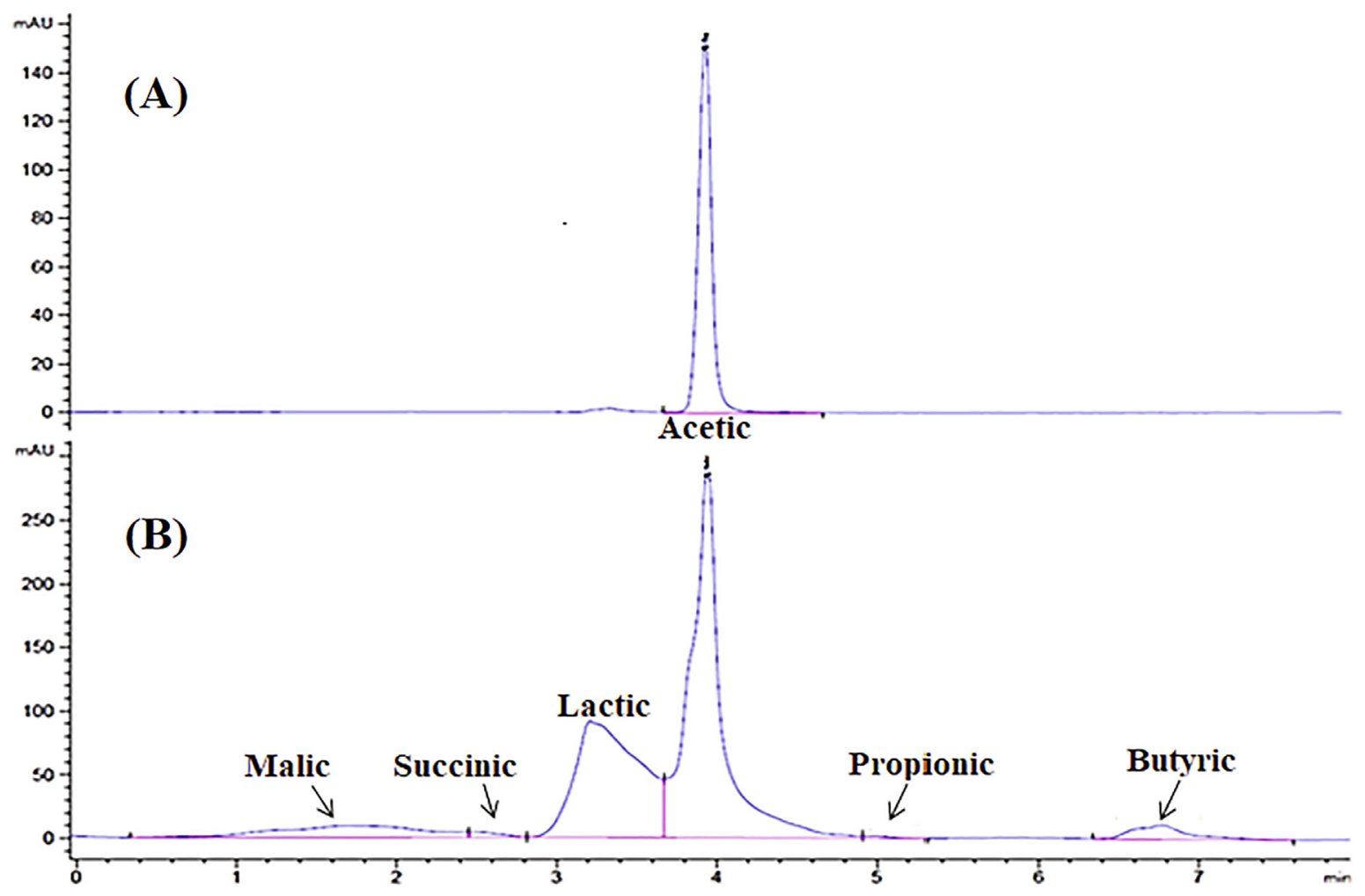

Fig. 1. HPLC chromatograms of (A) acetic acid and (B) VFAs in EGF sample.

supplement of power source (Keithley 2230-30-1 Triple Channel DC Power Supply, US) at an additional voltage of $1.0 \mathrm{~V}$ into the reactor. The BES was run in duplicate for more than six months at room temperature $\left( \pm 26^{\circ} \mathrm{C}\right)$. After each BES cycle, the anode was refilled with the fresh EGF as a substrate. Then the ultra-high purity nitrogen gas (99.99\%) was purged for $5 \mathrm{~min}$ to eliminate oxygen in the media. Meanwhile, the cathode was drained and exposed to the air to prevent methanogens growth and before refilled with fresh catholyte [27]. BES with GF/Pt cathode was used as a control in this study.

\subsection{Electrochemical analysis}

The voltammetry analysis, such as cyclic voltammetry (CV) and/or linear sweep voltammetry (LSV), can be used to evaluate the catalytic properties of materials [28]. In this study, only the LSV method was used to assess Ni-Fe catalytic performance based on the transformed Butler-Volmer equation, as described by Salembo et al.[11]. From the LSV scans, the currents (I, A) data were converted to the absolute value of current densities $\left(\mathrm{J}, \mathrm{A} / \mathrm{m}^{2}\right)$ and later to the log value of the absolute value of $J$. The Tafel plot was obtained by plotting the absolute value of current density $(J)$ against voltage $(\mathrm{V})$. The slope of the Tafel plot can be generated by fitting the straight line from the data points at the onset potential. The electrochemical cell was arranged under a three-electrode configuration, in which the tested materials were working as an electrode (WE), $\mathrm{Ag} / \mathrm{AgCl}$ ( $\mathrm{RE} \mathrm{5B}, \mathrm{MF}-2079$ ) as a reference electrode (RE), and anode as the counter electrode (CE). The LSV tests were performed by using a potentiostat (Autolab PGSTAT128N, Netherlands) at the potential in the range of $-1.2 \mathrm{~V}$ to $0.2 \mathrm{~V}$ with a scan rate of $3 \mathrm{mV} / \mathrm{s}$.

The electrochemical impedance spectroscopy (EIS) was used to evaluate the cathodic impedance of BES. Similarly, the EIS tests were carried out by using a potentiostat (Autolab PGSTAT128N, Netherlands) in a frequency range of $100 \mathrm{kHz}$ to $5 \mathrm{mHz}$, AC amplitude of $10 \mathrm{mV}$ scan rate of $25 \mathrm{mV} / \mathrm{s}$ and steady-state at the open circuit of BES [22]. The EIS measurements were conducted by in-situ tests, where the cathode worked as a WE. During the experiment, the $\mathrm{Ag} / \mathrm{AgCl}$ (RE $5 \mathrm{~B}, \mathrm{MF}-2079$ ) electrode in the cathode compartment was also used as $\mathrm{RE}$ while the anode was used as a CE. All impedance spectra were converted to the equivalent circuit, in which $R_{s}$ and $R_{p}$ symbols represented series and parallel resistances, respectively. The impedance spectra provide some information including the solution resistance, capacitances, and charge transfer and double-layer resistances.

\subsection{Gas analysis and calculations}

Biogas was collected using a $25 \mathrm{~mL}$ vial. Then, the biogas was analyzed using a gas chromatograph equipped with thermal conductivity detector (GC-TCD, GC-HP 4890D USA) with Altech Molesieve $5 \mathrm{~A}, 80 / 100$ as a column at an injector and column temperatures of $120^{\circ} \mathrm{C}$ and $180{ }^{\circ} \mathrm{C}$, respectively. The percentage of gas was determined based on the peak area of each gas.

The BES performance can be determined based on hydrogen yield $\left(Y_{\mathrm{H} 2}, \mathrm{~mL} / \mathrm{mL} \mathrm{COD}\right)$ (Eq. (4)), cathodic hydrogen recovery $\left(\mathrm{rH}_{2[} \mathrm{cat}_{]}\right)$ (Eq. (5)), and hydrogen production rate $\left(Q_{\mathrm{H} 2}, \mathrm{~mL} \mathrm{H}_{2} / \mathrm{mL}\right.$ of the anode) (Eq. (6)). [7,11], All parameters were calculated based on the following formula:

$Y \mathrm{H} 2=\frac{n_{\mathrm{H} 2} M_{\mathrm{H} 2}}{V_{1} \Delta \mathrm{COD}}$

$r \mathrm{H} 2[\mathrm{cat}]=\frac{n \mathrm{H}_{2}}{n \mathrm{H}_{2}[\mathrm{CE}]}$

$Q \mathrm{H} 2=\frac{\left(V \mathrm{H}_{2}\right)}{\left.\left(V_{\text {anode }}\right) \mathrm{xday}\right)}$

Where, $n \mathrm{H}_{2}$ and $M_{\mathrm{H} 2}$ are the number of moles and molecular mass of $\mathrm{H}_{2}$, respectively. The $n \mathrm{H}_{2}$ can be calculated based on an ideal gas formula (PV/RT) at standard condition and $M_{\mathrm{H} 2}$ is $2.0 \mathrm{~g} / \mathrm{mol} . \Delta \mathrm{COD}$ is the amount of change in COD based on the COD of the substrate at the beginning (CODo) and final (CODs) of BES run. The $n \mathrm{H}_{2}[\mathrm{CE}]$ is the amount of hydrogen mole that can be calculated based on the measured 
current from BES run $=\frac{\int_{0}^{\mathrm{t}} I d t}{2 \mathrm{~F}}$, Idt is the continuous measured BES current, and $\mathrm{F}$ is Faraday constant $(96485 \mathrm{C} / \mathrm{mol}) . V_{\mathrm{H} 2}$ and $V_{\text {anode }}$ are volumes of hydrogen and anode of BES, respectively.

The energy efficiency ( $\eta \mathrm{E}, \%)$ of the system is the amount of energy produced by hydrogen generation $\left(W_{\mathrm{H} 2}, \mathrm{~kJ}\right)$ over the amount of energy added into the system ( $W_{\mathrm{E}}, \mathrm{kJ}$ ) (Eq. (7)). $W \mathrm{E}$ and $W_{\mathrm{H} 2}$ are calculated based on Eq. (8) and (9) as follow;

$\eta \mathrm{E}=\frac{W \mathrm{E}}{W \mathrm{H}_{2}}$

$W \mathrm{E}=\sum_{0}^{t}\left(\left(I x E_{a p} x \Delta t\right)-\left(I^{2} x R_{e x} x \Delta t\right)\right)$

$W \mathrm{H} 2=\left(n_{\mathrm{H} 2} \mathrm{x} \Delta H_{\mathrm{H} 2}\right)$

where $I(\mathrm{~A})$ is the amount of current produced from the system, $E_{a p}$ $(1.0 \mathrm{~V})$ is the amount of voltage supplied into the system using a power source, $R_{e x}(1 \mathrm{O})$ is an external resistance applied in the system, $\Delta H_{\mathrm{H} 2}$ $(285.83 \mathrm{~kJ} / \mathrm{mol})$ is the energy content of hydrogen-based on the heat combustion and $t(\mathrm{~h})$ is period of data collection.

\section{Results and discussion}

\subsection{Characterization of GF, GF/Pt and Ni-Fe electrodes}

The acid and base treatments are important steps to remove organic and inorganic impurities on the electrode surfaces. The cleaned GF surface was then enriched with EAB using anaerobic sludge of palm oil mill effluent (POME) as the inoculum source. The enrichment process allows the EAB can attach on the GF surface to form a biofilm. In addition, the presence of specific interaction mediated by biological forces drives the attachment of microorganisms on the material surface. [29]. As shown in Fig. 2(A), the SEM image of GF surface is clean and smooth at the startup of BES operation. Meanwhile, Fig. 2(D) shows the GF surface is covered by EAB after six months of BES operation. The EAB acts as biocatalyst at the anode that can enhance the anode performance to generate protons and electrons from substrate. The robustness of bioanode to maintain its biocatalytic activity affects the performance of the whole system [30]. Whereas, Fig. 2 (B) shows a Pt catalyst layer is covered the GF surface after the coating process. Based on the EDX result, the composition of the Pt catalyst is obtained $1.2 \%$ (Table 1). At startup of BES operation, the GF/Pt performance is high but its performance is gradually dropped after six months. This phenomenon might due to the presence of salts or other impurities covered the GF/Pt surface (Fig. 1(E)), consequently, the activity of Pt catalyst is decreased to generate hydrogen. Similarly, the performance of Ni-Fe cathode is high in early of BES operation and later decreased after six months. Fig. 2(C) shows the Ni-Fe surface is still clean and smooth after the acidbase treatments while Fig. 2(F) shows Ni-Fe is corroded and covered by salts or other impurities. Based on the EDX analysis (see Table 1), the compositions of $\mathrm{Ni}$ and $\mathrm{Fe}$ on the surface were reduced from $99.4 \%$ to $12.2 \%$ and $0.6 \%$ to ND $(\sim 0.0 \%)$, respectively. This fact showed that the presence of salts or impurities layer and the decrease in Fe composition on the Ni material can reduce the electro-catalytic activity for HER [19].

\subsection{Cathode catalytic Properties: Ni-Fe vs GF/Pt control}

Catalytic performance of both Ni-Fe and GF/Pt were evaluated by using LSV tests. As shown in Fig. 3, two linear regions are represented (A and B), Butler-Volmer kinetic or high current density (dash line) and resistive kinetic or low current density (solid line). Based on Tafel slope, the cathodic transfer coefficient $\left(\alpha_{c}\right)$ and a number of electrons $\left(n_{e}\right)$ during the reactions can be determined by using Eq. (10), where $J$ and $J_{o}$ are current density $\left(\mathrm{A} / \mathrm{cm}^{2}\right)$ and exchange current density $\left(\mathrm{A} / \mathrm{cm}^{2}\right), E$ and $E_{o}$ are working potential $(\mathrm{V})$ and equilibrium potential $(\mathrm{V}), \mathrm{F}$ is
Faraday constant $(96485 \mathrm{C} / \mathrm{mol}), \mathrm{R}$ is the ideal gas constant $(8.31 \mathrm{~J} / \mathrm{mol}$ $\mathrm{K})$, and $\mathrm{T}$ is the temperature $(\mathrm{K})$, as follows:

$\log J=\log J o+\frac{\alpha_{c} n_{e} \mathrm{~F}}{2.303 \mathrm{RT}}\left(E-E_{0}\right)$

As mentioned above, the catalytic performance can be referred based on the Tafel slope and $y$-intercept, in which the high Tafel slope indicates the high catalytic properties [31]. Principally, the catalytic performance (either in anodic or cathodic reaction) can be determined based on the data points around the onset potential at where the current starts to increase steeply. In this study, the onset potentials for GF/Pt and $\mathrm{Ni}-\mathrm{Fe}$ are observed in the range of $0.0 \mathrm{~V}$ to $-0.2 \mathrm{~V}$. This study found that the Tafel slope of -23.5220 and y-intercept of 4.4840 for GF/ Pt is steeper than the Tafel slope of 23.0460 and y-intercept of 8.1435 for Ni-Fe. Tafel slope results can be used as a logical reason to explain the high BES performance when using GF/Pt compared to Ni-Fe. The cost of Ni-Fe (USD $15.36 \mathrm{USD} / 25 \mathrm{~cm}^{2}$ ) [32] is relatively cheaper than GF/Pt (USD 25.04/ $\mathrm{cm}^{2}$ ) [33], making the Ni-Fe as one of the feasible alternatives in BES for hydrogen production.

\subsection{Assessment of internal resistances}

EIS analysis was carried out on the cathode in the steady-state of BES. It is well known that the impedance analysis can generate the Nyquist plots and types of internal resistance. Fig. 4 (A and B) indicates the circuit of BES by using Ni-Fe and GF/Pt cathodes, respectively. Principally, a BES circuit consists of five types of internal resistance $\left(R_{\text {in }}\right)$, namely one resistance connected in series $\left(R_{s}\right)$ with two parallel $\left(R_{p}\right)$ resistances. Generally, the $R_{s}$ or ohmic resistance represents the resistance from the solution, separator and electrode, meanwhile, one of the $R_{p}$ represents the charge transfer resistance and second of the $R_{p}$ represents the diffusion resistance [34,35]. Generally, more than $51 \%$ of $R_{\text {in }}$ is contributed by $R_{s}$, while the charge transfer contributed around $23 \%$, and the rest is due to the diffusion effect [35].

Based on the Nyquist plot, as shown in Fig. 4(C), the distance from coordinates origin to the beginning of the first semi-circle corresponds to the $R_{s}$ and the diameters of the first and second semi-circles correspond to the first and second $R_{p}$, respectively [36]. For instance, the circuit of BES with Ni-Fe, in which $R_{s}$, the first $R_{p}$ and the second $R_{p}$ are observed $6.91 \Omega, 10.1 \Omega$ and $163 \Omega$, respectively (Fig. 4(A)). From these data, the $\mathrm{R}_{\text {in }}$ of Ni-Fe obtained up to $7.02 \Omega$ is quite higher than the $\mathrm{R}_{\text {in }}$ of $3.43 \Omega$ for GF/Pt. These data indicate that BES by using both Ni-Fe and GF/Pt have good electrochemical behavior and high conductivity because the $R_{\text {in }}$ are relatively low $(<10 \Omega)$. The internal resistance acclaims having a critical factor in the current and cations transfer. The high internal resistance reduces the number of transferred electrons and protons from the anode to cathode, consequently, the volume of hydrogen gas formation is low [37].

\subsection{Electrolyte conditions}

Anolyte (EGF) condition, such as $\mathrm{pH}$ and organic substrates (nutrients) are a few essential factors for consideration in hydrogen production [38]. Low $\mathrm{pH}(\mathrm{pH}<5)$ and limiting nutrients affect the ability of the culture for biogas and VFAs or alcohols formation [39]. It is well known that the type of products are significantly related to the type of inoculums or microorganisms used in the fermentation process $[40,41]$. Based on the previous analysis, the effluent of glucose fermentation generally consists of acetic acid as the primary organic acid. In our previous work [18], the mixed-culture from anaerobic sludge of palm oil mill effluent (POME) was used as a source of inoculum in the fermentation. As reported in Table 2, the acetic and lactic acids are the primary organic acids in EGF with the composition of $52.97 \%(\mathrm{v} / \mathrm{v})$ and $34.59 \%(\mathrm{v} / \mathrm{v})$, respectively. Based on this report, we assumed that the EGF is suitable as a substrate in BES for generating hydrogen.

Besides, EGF conductivity facilitates the transportation of both 

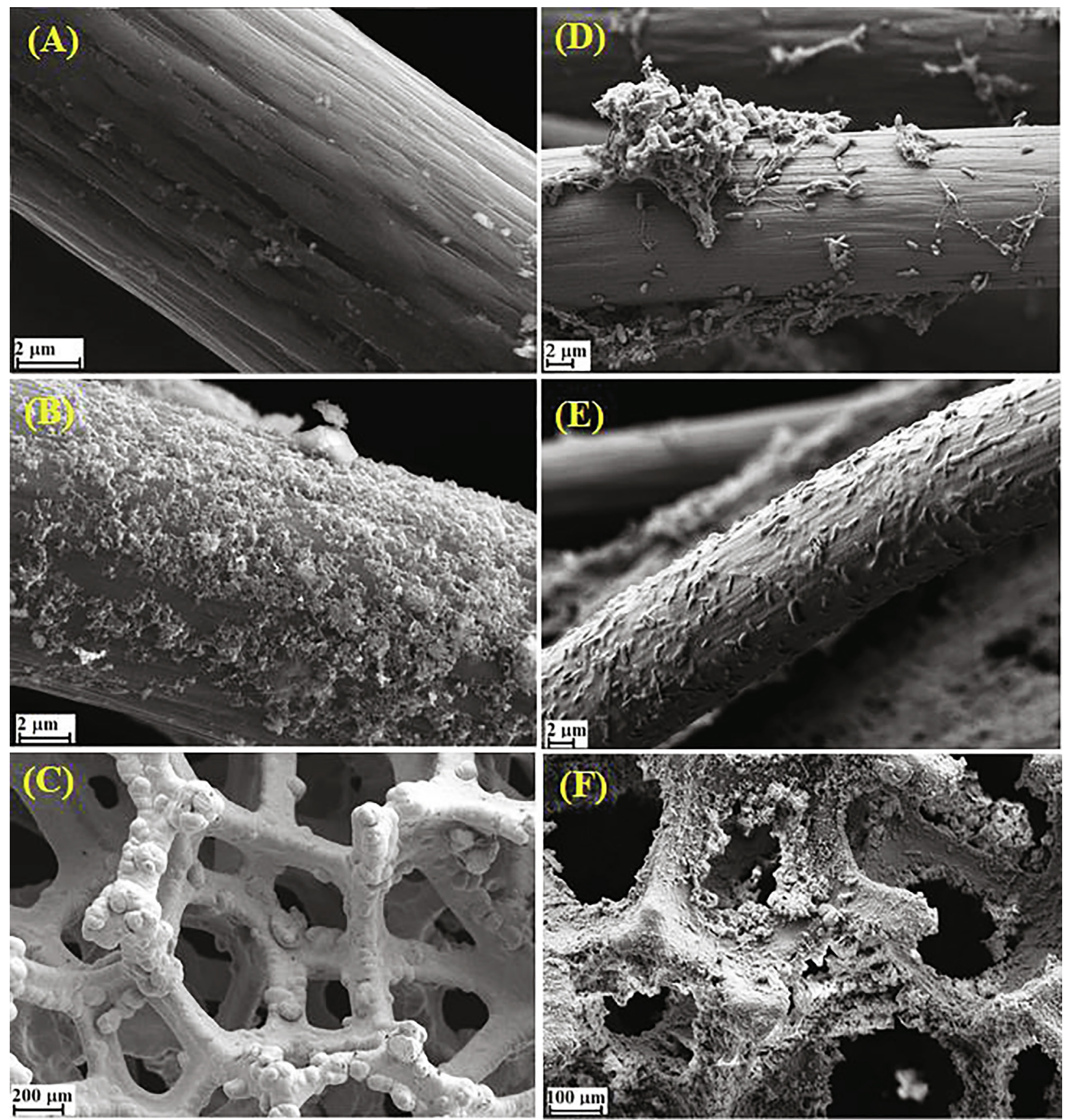

Fig. 2. SEM images of GF anode (A), GF/Pt (B) and Ni-Fe (C) at startup, while GF anode (D), GF/Pt (E) and Ni-Fe (E) after six months of BES operation.

electrons and protons from solution to the solid anode. Low EGF conductivity reduces the number of transferred electrons and protons at the cathode compartment; consequently, the product formation is low [42]. Therefore, the treatment process on EGF is needed to recover $\mathrm{pH}$ and conductivity. Due to the low $\mathrm{pH}$ of $\mathrm{EGF}(\mathrm{pH}= \pm 5)$, a base solution can increase the $\mathrm{pH}$ value and conductivity simultaneously. Treatment of EGF with $\mathrm{Na}_{2} \mathrm{HPO}_{4}(2 \mathrm{M})$ increases their $\mathrm{pH}$ and conductivity, as shown in Table 3. From Table 3, pH and EGF conductivity are increased from 5.0 and $10.31 \mathrm{mS} / \mathrm{cm}$ (before treatment) to 7.0 and $15.84 \pm 0.03 \mathrm{mS} /$ $\mathrm{cm}$ (after treatment), respectively. This fact proved that the more ions dissolved into the solution result in higher solution conductivity [43]. Based on these results, EGF is ready to be used in further experiments.

Theoretically, an anode compartment is a place where dissolved charged ions, including electrons and protons, are generated. The electrons are then transferred into the cathode via external circuit while the cations go through a separator; hence, the number of dissolved charged ions at the anode (in anolyte) are decreased over time. The electrons and ions movement are the logical reason to explain why the anolyte conductivity of Ni-Fe decreased to $13.08 \mathrm{mS} / \mathrm{cm}$ at the end of the BES operation. On the contrary, accumulation of the dissolved ions at the cathode compartment increases the catholyte conductivity to $17.10 \mathrm{mS} / \mathrm{cm}$. Similarly, $\mathrm{pH}$ value of anolyte also decreases to 5.68 which is caused by the presence of a separator, consequently, the transportation of organic acid ions to the cathode is not optimal $[44,45]$. On the other hands, the $\mathrm{pH}$ value of catholyte is increased to 11.93, this fact might due to the accumulation of alkali ions at the cathode compartment.

\subsection{Hydrogen production}

The main target of this study is to generate hydrogen from EGF by using BES with Ni-Fe cathode. Table 4 shows the cathodic hydrogen 

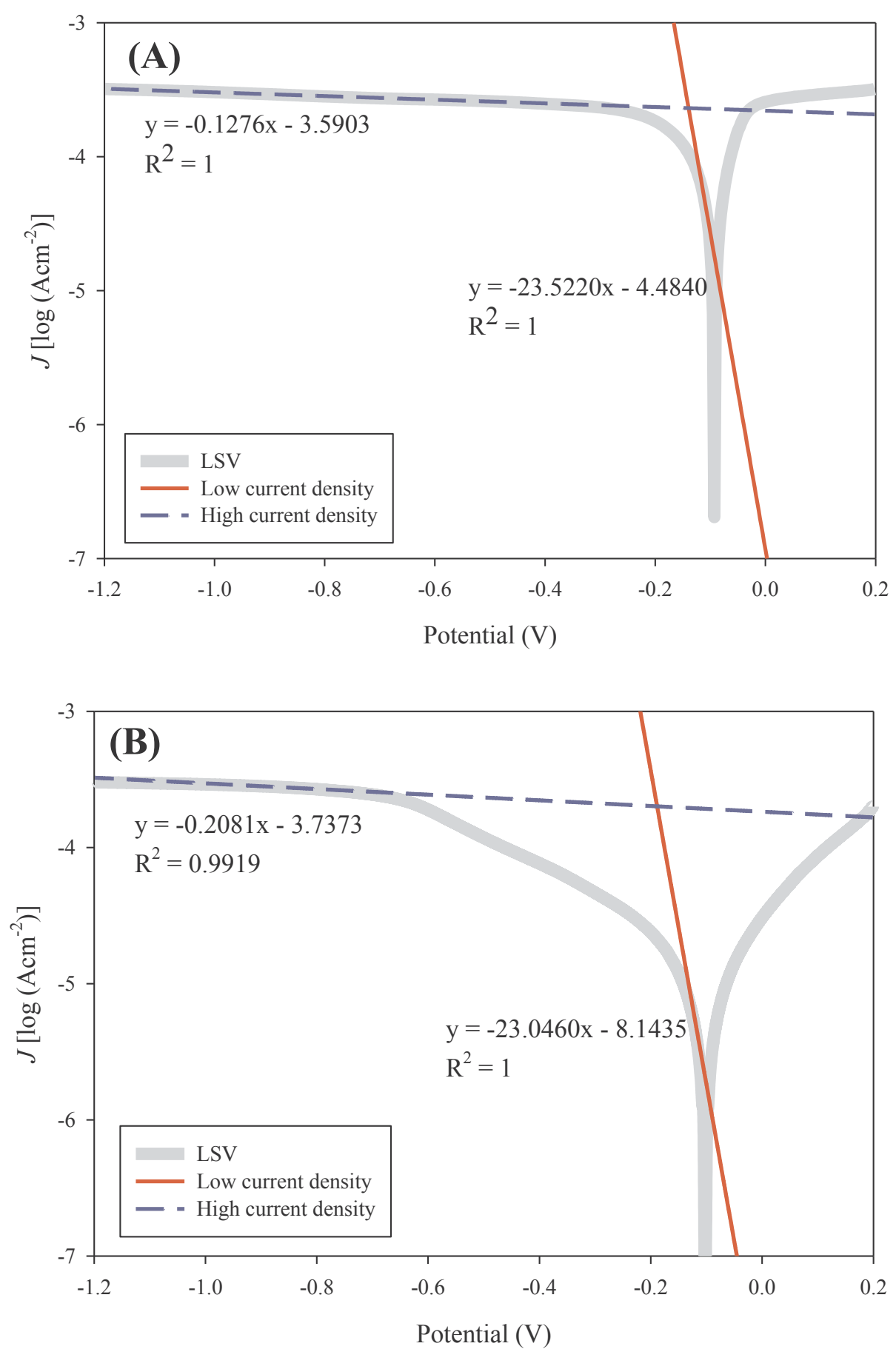

Fig. 3. LSV scans with high and low current density for (A) GF/Pt and (B) Ni-Fe.

recovery $\left(\mathrm{rH}_{2}\right.$ [cat]), yield $\left(\mathrm{Y}_{\mathrm{H} 2}\right)$ and production rate $(\mathrm{QH} 2)$ using $\mathrm{Ni}-\mathrm{Fe}$ in comparison to stainless steel (SS) and carbon cloth coated with platinum (CC/Pt). Overall, Ni-Fe shows the comparable performance with GF/Pt control and references. In fact, the hydrogen yield and volumetric current density $\left(I_{V}\right)$ of Ni-Fe are much higher compared to SS [46]. In terms of hydrogen composition, Ni-Fe is quite similar to GF/ $\mathrm{Pt}$ control. Hence, Ni-Fe is one of the right options for the alternative cathode to GF/Pt cathode in BES.

Furthermore, as shown in Fig. 5, the trends of hydrogen production are gradually increased with increase in supplied voltage from $0.6 \mathrm{~V}$ to $1.0 \mathrm{~V}$. Logically, increase in the electrical power input into BES accelerates the electrolysis processes, and consequently increases the hydrogen volume [47]. However, the hydrogen production is quite constant at $1.0 \mathrm{~V}$ and $1.2 \mathrm{~V}$ of applied voltage. This phenomenon might due to the BES performance is closely related with the ability of bioanode to supply electrons and protons. Lim et al. [30] reported that the strength of bioanode is the limiting factor in BES system. The bound electrons and protons output at bioanode could halt the cathode capability to generate hydrogen. This study showed that the maximum hydrogen volume for Ni-Fe and GF/Pt are obtained $32 \mathrm{~mL}$ and $40 \mathrm{~mL}$, respectively, at $1.0 \mathrm{~V}$ of applied voltage. This stage was then assumed as the optimum condition for BES operation. Besides the bioanode ability and catalytic properties of the cathode, the presence of separator also plays a crucial role in BES performance as a whole. 
(A)

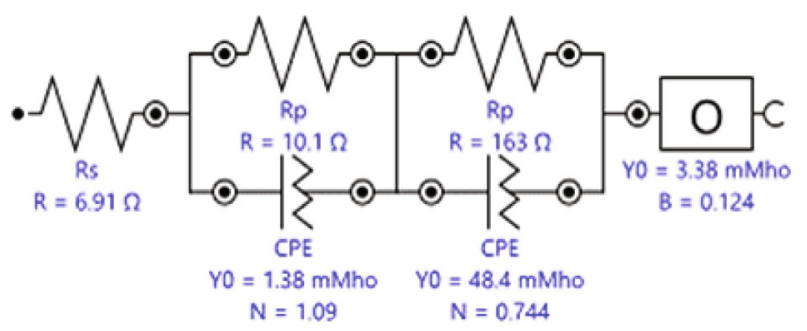

(B)

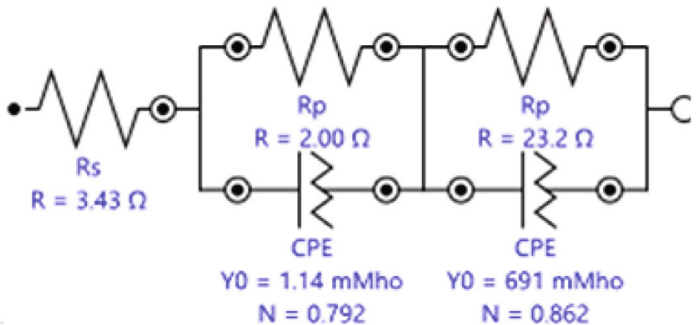

(C)

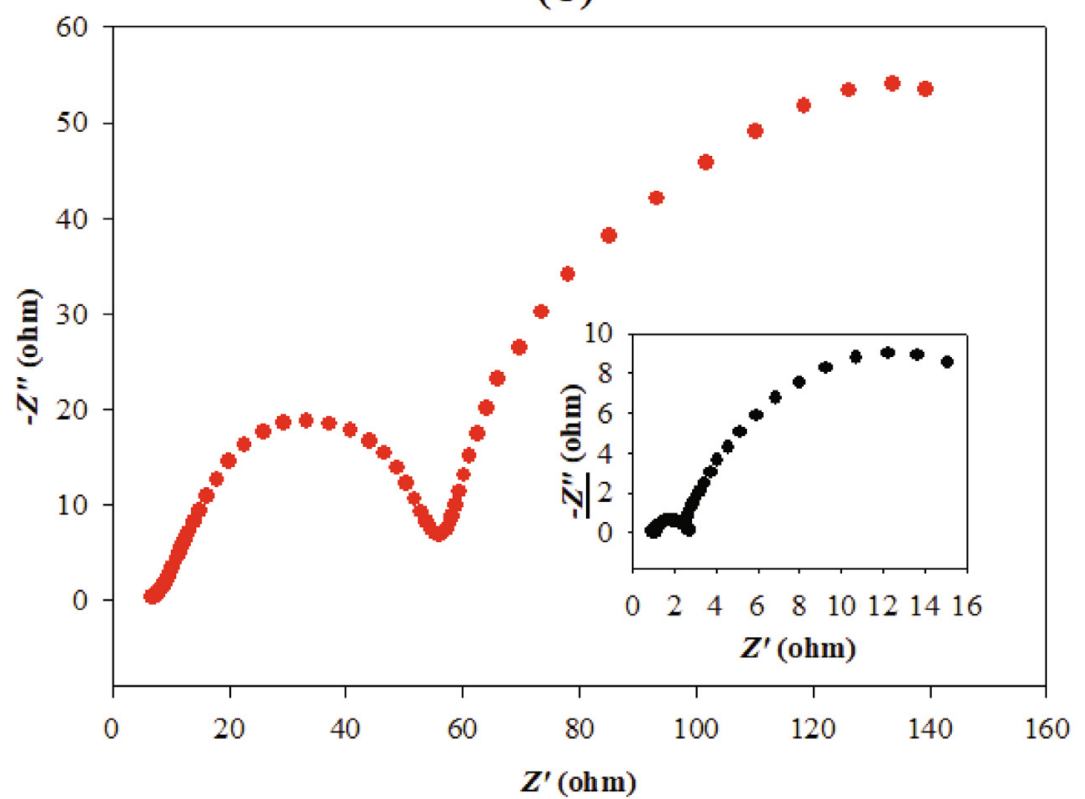

Fig. 4. Type of fitting circuits for (A) Ni-Fe, (B) GF/Pt control and (C) Nyquist plots of impedance spectra for Ni-Fe and inset for GF/Pt.

Table 3

Summary of anolyte and catholyte conditions before and after experimental runs.

\begin{tabular}{|c|c|c|c|c|c|}
\hline \multirow[t]{2}{*}{ Cathodes } & \multicolumn{2}{|l|}{$\mathrm{pH}$} & \multicolumn{2}{|c|}{ Electrical conductivity (mS/cm) } & \multirow[t]{2}{*}{$\operatorname{COD}(\mathrm{g} / \mathrm{L})$} \\
\hline & Anolyte & Catholyte & Anolyte & Catholyte & \\
\hline \multicolumn{6}{|c|}{ Before treated with $\mathrm{Na}_{2} \mathrm{HPO}_{4}$ * } \\
\hline $\mathrm{GF} / \mathrm{Pt}^{* *}$ & $5.01 \pm 0.01$ & $7.01 \pm 0.01$ & $10.42 \pm 0.02$ & $13.08 \pm 0.02$ & - \\
\hline $\mathrm{Ni}-\mathrm{Fe}$ & $5.01 \pm 0.01$ & $7.01 \pm 0.01$ & $10.31 \pm 0.03$ & $13.08 \pm 0.02$ & - \\
\hline \multicolumn{6}{|c|}{ Starting BES run: After treated with $\mathrm{Na}_{2} \mathrm{HPO}_{4}$ * } \\
\hline $\mathrm{GF} / \mathrm{Pt}^{* *}$ & $7.01 \pm 0.01$ & $7.01 \pm 0.01$ & $15.84 \pm 0.03$ & $13.08 \pm 0.02$ & $1.61 \pm 0.11$ \\
\hline $\mathrm{Ni}-\mathrm{Fe}$ & $7.01 \pm 0.01$ & $7.01 \pm 0.01$ & $15.84 \pm 0.03$ & $13.08 \pm 0.02$ & $1.61 \pm 0.11$ \\
\hline \multicolumn{6}{|c|}{ End of BES run } \\
\hline $\mathrm{GF} / \mathrm{Pt}^{* *}$ & $5.78 \pm 0.02$ & $12.20 \pm 0.02$ & $13.00 \pm 0.02$ & $18.25 \pm 0.02$ & $0.91 \pm 0.11$ \\
\hline $\mathrm{Ni}-\mathrm{Fe}$ & $5.68 \pm 0.02$ & $11.93 \pm 0.01$ & $13.08 \pm 0.02$ & $17.10 \pm 0.02$ & $0.81 \pm 0.01$ \\
\hline
\end{tabular}

* Anolyte (EGF) was treated with $\mathrm{Na}_{2} \mathrm{HPO}_{4} ; *$ GF/Pt control cathode

Table 4

Summary of BES using Ni-Fe performance compared with GF/Pt control and references.

\begin{tabular}{|c|c|c|c|c|c|c|c|c|c|c|c|c|}
\hline Cathode & Substr. & $E_{a p}(V)$ & $\mathrm{CE}(\%)$ & $r \mathrm{H}_{2}[\mathrm{COD}](\%)$ & $\left.r \mathrm{H}_{2[} \mathrm{cat}\right](\%)$ & $\eta \mathrm{E}(\%)$ & $\eta \mathrm{E}+\mathrm{S}(\%)$ & $I_{v}\left(\mathrm{~A} / \mathrm{m}^{3}\right)$ & $Y_{\mathrm{H} 2}\left(\mathrm{~mL} / \mathrm{g}_{\mathrm{COD}}\right)$ & $Q_{\mathrm{H} 2}(\mathrm{~mL} / \mathrm{L} / \mathrm{d})$ & $\mathrm{H}_{2}(\%)$ & Ref. \\
\hline $\mathrm{GF} / \mathrm{Pt}$ & EGF & 1.0 & $98.3 \pm 0.7$ & $44 \pm 4$ & $46 \pm 4$ & $138 \pm 13$ & $38 \pm 4$ & $116 \pm 10$ & $553.6 \pm 53.5$ & $590 \pm 10$ & $71 \pm 4$ & This study \\
\hline $\mathrm{Ni}-\mathrm{Fe}$ & EGF & 1.0 & $97.8 \pm 0.8$ & $41 \pm 1$ & $43 \pm 4$ & $135 \pm 24$ & $36 \pm 2$ & $101 \pm 16$ & $470.2 \pm 11.2$ & $500 \pm 80$ & $69 \pm 4$ & This study \\
\hline CC/SSM & EGF & 1.0 & $29.9 \pm 2.3$ & $35 \pm 2$ & $215 \pm 18$ & $68 \pm 5$ & $86 \pm 8$ & $56 \pm 2$ & $330 \pm 30$ & $16 \pm 0^{*}$ & NA & [46] \\
\hline $\mathrm{CC} / \mathrm{Pt}$ & EGF & 0.9 & $110 \pm 20$ & $52 \pm 19$ & $49 \pm 16$ & $150 \pm 50$ & NA & NA & $800 \pm 290^{*}$ & $590 \pm 210$ & NA & [48] \\
\hline Ni 201 & Acetate & 0.9 & NA & $26 \pm 3$ & $27 \pm 4$ & $46 \pm 7$ & $20 \pm 3$ & $127 \pm 8$ & NA & $380 \pm 40$ & $57 \pm 3$ & [11] \\
\hline $\mathrm{Ni} 400$ & Acetate & 0.9 & NA & $31 \pm 8$ & $31 \pm 5$ & $53 \pm 9$ & $23 \pm 5$ & $116 \pm 9$ & NA & $410 \pm 100$ & $62 \pm 8$ & [11] \\
\hline Pt metal & Acetate & 0.9 & NA & $46 \pm 4$ & $47 \pm 2$ & $81 \pm 3$ & $35 \pm 3$ & $129 \pm 7$ & NA & $680 \pm 60$ & $74 \pm 2$ & [11] \\
\hline
\end{tabular}

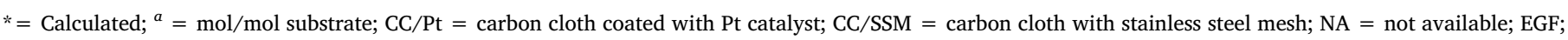
effluent of glucose fermentation 


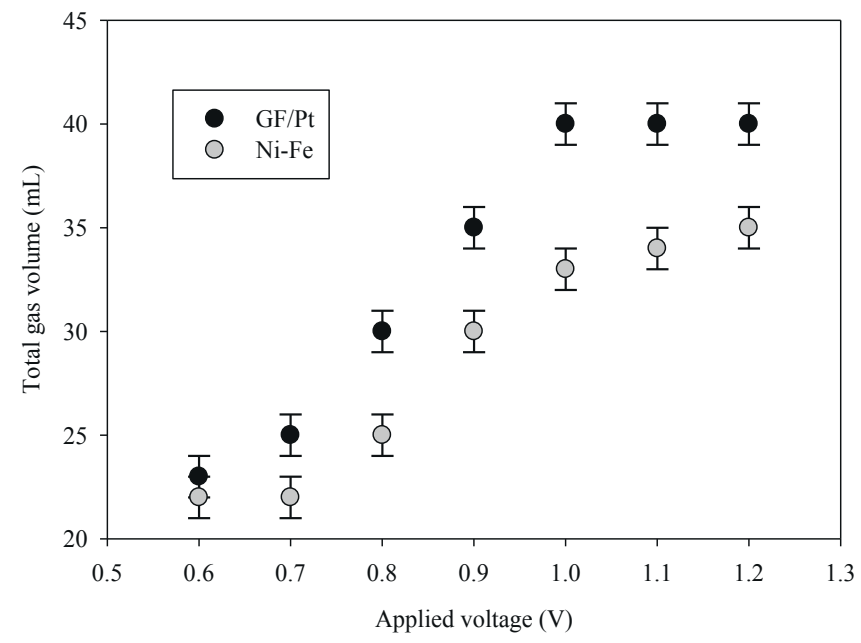

Fig. 5. Trends of total biogas and hydrogen production from EGF using GF/Pt (black circle) and Ni-Fe (grey circle) at $0.6 \mathrm{~V}-1.2 \mathrm{~V}$ of applied voltage. All data were collected during BES operation in the range of one to six months.

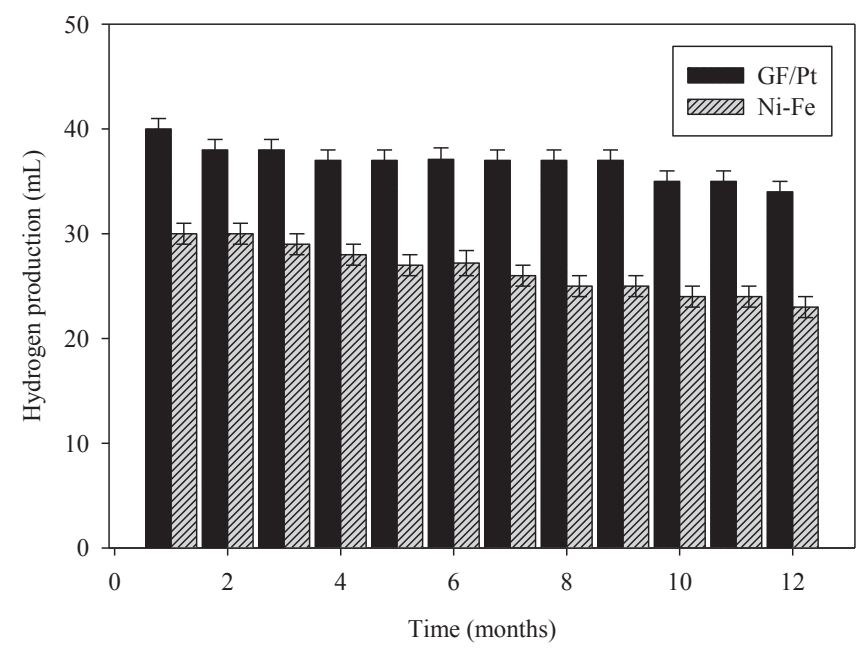

Fig. 6. Trends hydrogen production for twelve months of BES operation.

\subsection{GF-anode and Ni-Fe-cathode performance over time}

In most cases, the anode in a microbial fuel cell (MFC) is also suitable in BES for hydrogen production [49]. The EAB biofilm at the GF anode has a significant contribution to BESs performance, in which the EAB biofilm can reduce the anode potential and polarization resistance [50]. Therefore, the anode must be initially enriched with electroactive bacteria by using anaerobic sludge or digester before it was used further in BES experiments. As shown in section 1, the EAB biofilm is attached to the GF-anode surface after six months of operation (see Fig. 2(D)). At this stage, the optimum hydrogen production is obtained $32 \mathrm{~mL}$.

Principally, the catalytic properties of metals are gradually decreased over time [11]. This phenomenon might due to the presence of an oxide layer or corrosion reaction on the metal surface. During the electrolysis processes, Ni-Fe has been continuously explored with the electrical current $\left(2 \mathrm{Ni} \rightarrow 2 \mathrm{Ni}^{2+}+4 e^{-}\right)$and/or $\left(\mathrm{Fe} \rightarrow \mathrm{Fe}^{2+,} 3++2 e^{-}\right.$, $\left.3 e^{-}\right)$, and oxygen $\left(\mathrm{O}_{2}+4 e^{-} \rightarrow 2 \mathrm{O}^{2-}\right)$, consequently the cathode is oxidized to nickel oxide (NiO) and/or iron (II) oxide/iron (III) oxide (FeO/ $\mathrm{Fe}_{2} \mathrm{O}_{3}$ ). As shown in Fig. 2(F) (Section 3.1), the SEM image is visually indicated a change in Ni-Fe morphology. However, surface chemical compositions are not included in this study. Also, the presence of microorganisms at the cathode surface can accelerate either the oxidation-reduction [51] or corrosion reactions [52]. This phenomenon might help to explain why BES performance gradually decreased with long term BES operation. The decrease in BES performances are shown in Fig. 6, in which trends of the hydrogen production are decreased from $32 \mathrm{~mL}$ to $27 \mathrm{~mL}$ after six months of BES operation.

BES performance is associated with the limiting factor of bioanode, $\mathrm{Ni}-\mathrm{Fe}$ cathode properties and type of separator (in dual BES system). Hence, a few approaches are required to maintain the BES performance. An anode ability can be enhanced by choosing the available material such as GF. A suitable material is additional to the treatment and enrichment process of $\mathrm{EAB}$ at the anode compartment, and by removing separator from the system. For the cathode, as discussed above, the decrease in Ni-Fe catalytic properties might due to the presence of metal oxide (might be iron oxide) layer on the surface. The electroplating technique is one of the methods able to prevent or reduce the oxidation-reduction and/or corrosion reactions of metal. Electroplating entails electrodeposition of metal onto the Ni-Fe surface. The coated metal particles on the surface acted as a sacrificial barrier to prevent corrosion reaction. Several metals can be deposited on the Ni-Fe surface, such as the precious metal gold (Au) and silver (Ag) or non-precious copper $(\mathrm{Cu})$, cobalt $(\mathrm{Co})$, molybdenum (Mo), tungsten (W), titanium (Ti) and chromium (Cr) [53]. However, the cost of the process and the catalytic properties of coated metal must be seriously considered for their performance to be consistently high.

\section{Conclusion}

The Ni-Fe properties play a crucial role in hydrogen production from EGF in the BES. In terms of catalytic properties, Ni-Fe shows a comparable performance with $\mathrm{GF} / \mathrm{Pt}$, in which the Tafel slope of -23.0460 for Ni-Fe as compared to -23.5520 for GF/Pt. The BES using $\mathrm{Ni}$-Fe cathode can be generate hydrogen from EGF, in which the cathodic hydrogen recovery, hydrogen yield, production rate and purity are obtained up to $43 \%, 470.2 \mathrm{~mL} / \mathrm{g}$ COD, $500 \mathrm{~mL} / \mathrm{mL} / \mathrm{d}$, and $69 \%$, respectively, at $1.0 \mathrm{~V}$ of applied potential. Performance of Ni-Fe as an alternative cathode is feasible to replace GF/Pt. Exclusively, this study illustrated that the fermentation could be integrated with the BES system.

\section{Conflict of interest}

Indeed, one of characteristics of non-precious metal is easy to be corroded by the supply current, consequently, the Ni-Fe performance was dropped after more than six months BES run. However, we predict this problem can be solved by using electroplating method. Therefore, in here, all the authors have no conflict interest to declare.

\section{Declaration of Competing Interest}

The authors declare that they have no known competing financial interests or personal relationships that could have appeared to influence the work reported in this paper.

\section{Acknowledgements}

The authors gratefully acknowledge the financial support given by the Universiti Kebangsaan Malaysia via the research sponsorships of MI-2018-015.

\section{References}

[1] D.R. Lovley, K.P. Nevin, A shift in the current: new applications and concepts for microbe-electrode electron exchange, Curr Opin Biotechnol 22 (2011) 441-448.

[2] S. Bajracharya, M. Sharma, G. Mohanakrishna, X.D. Benneton, D.P.B.T.B. Strik, P.M. Sarma, D. Pant, An overview on emerging bioelectrochemical systems (BESs): Technology for sustainable electricity, waste remediation, resource recovery, chemical production and beyond, Renew, Energy 98 (2016) 153-170.

[3] C.G.S. Giddings, K.P. Nevin, T. Woodward, D.R. Lovley, C.S. Butler, Simplifying 
microbial electrosynthesis reactor design, Front Mirobiol 6 (468) (2015) 1-6.

4] H.V.M. Hamelers, A. Ter Heijne, T.H.J.A. Sleutels, A.W. Jeremiasse, D.P.B.T.B. Strik, C.J.N. Buisman, New applications and performance of bioelectrochemical systems, Appl Microbiol Biotechnol 85 (6) (2010) 1673-1685, https:// doi.org/10.1007/s00253-009-2357-1.

[5] R.A. Rozendal, H.V.M. Hamelers, G.J.W. Euverink, S.J. Metz, C.J.N. Buisman, Principle and perspectives of hydrogen production through biocatalyzed electrolysis, Int J Hydrogen Energy 31 (2006) 1632-1642.

[6] R.K. Thauer, K. Jungermann, K. Decker, Energy conservation in chemotrophic anaerobic bacteria, Bacteriol Rev 41 (1) (1977) 100-180.

[7] B.E. Logan, D. Call, S. Cheng, H.V.M. Hamelers, T.H.J.A. Sleutels, A.W. Jeremiasse, R.A. Rozendal, Microbial electrolysis cells for high yield hydrogen gas production from organic matter, Environ Sci Technol 42 (2008) 8630-8640.

[8] L. Lu, Z.J. Ren, Microbial electrolysis cells for waste biorefinery: A state of the art review, Bioresour Technol 215 (2016) 254-264.

[9] R.A. Rozendal, H.V. Hamelers, K. Rabaey, J. Keller, C.J. Buisman, Towards practical implementation of bioelectrochemical wastewater treatment, Trends Biotechnol 26 (28) (2008) 450-459.

[10] A.J. Lewis, S. Ren, P. Ye, P. Kim, N. Labbe, A.P. Borole, Hydrogen production from switchgrass via a hybrid pyrolysis-microbial electrolysis process, Bioresour Technol 195 (2015) 231-241.

[11] P.A. Salembo, M.D. Merrill, B.E. Logan, The use of stainless steel and nickel alloys as low cost cathodes in microbial electrolysis cells, J Power Sources 190 (2009) 271-278.

[12] A.W. Jeremiasse, J. Bergsma, J.M. Kleijn, M. Saakes, C.J.N. Buisman, M.C. Stuart, H.V.M. Hamelers, Performance of metal alloys as hydrogen evolution reaction catalysts in a microbial electrolysis cell, Int J Hydrogen Energy 36 (2011) 10482-10489.

[13] H. Hu, Y. Fan, H. Liu, Optimization of NiMo catalyst for hydrogen production in microbial electrolysis cells, Int J Hydrogen Energy 35 (2010) 3227-3233.

[14] A. Kadier, Y. Simayi, K. Chandrasekhar, M. Ismail, M.S. Kalil, Hydrogen gas production with an electroformed Ni mesh cathode catalysts in a single-chamber microbial electrolysis cell (MEC), Int J Hydrogen Energy 40 (41) (2015) 14095-14103.

[15] A.W. Jeremiasse, H.V.M. Hamelers, M. Saakes, C.J.N. Buisman, Ni foam cathode enables high volumetric $\mathrm{H}_{2}$ production in a microbial electrolysis cell, Int J Hydrogen Energy 35 (2010) 12716-12723.

[16] N. Ullah, M. Xie, C.J. Oluigbo, Y. Xu, J. Xie, H. UrRasheed, M. Zhang, Nickel and cobalt in situ grown in 3-dimensional hierarchical porous graphene for effective methanol electro-oxidation reaction J Electroanal Chem $\mathrm{xxx}(\mathrm{xxx})(2019) \mathrm{xx}-\mathrm{xx}$.

[17] M. Atasoy, O. Eyice, A. Schnürer, Z. Cetecioglu, Volatile fatty acids production via mixed culture fermentation: Revealing the link between $\mathrm{pH}$, inoculum type and bacterial composition, Bioresour Technol 292 (2019) 121889.

[18] I. Satar, W.R.W. Daud, B.H. Kim, M.R. Somalu, M. Ghasemi, Immobilized mixedculture reactor (IMcR) for hydrogen and methane production from glucose, Energy 139 (2017) 1188-1196.

[19] M.J. Giz, S.C. Bento, E.R. Gonzales, NiFeZn codeposit as a cathode material for the production of hydrogen by water electrolysis, Int J Hydrogen Energy 25 (2000) 621-626.

[20] A. Alshammari, V.A. Kalevaru, A. Martin, Bimetallic Catalysts Containing Gold and Palladium for Environmentally Important Reactions, Catalyst 6 (97) (2016) 1-24.

[21] E.R. Llobet, J.Y. Nam, J.C. Tokash, A. Guisasola, B.E. Logan, Assessment of four different cathode materials at different initial pHs using unbuffered catholytes in microbial electrolysis cells, Int J Hydrogen Energy 38 (2013) 2951-2956.

[22] I. Satar, W.R.W. Daud, B.H. Kim, M.R. Somalu, M. Ghasemi, M.H.A. Bakar T. Jafary, S.N. Timmiati, Performance of titanium-nickel (Ti/Ni) and graphite feltnickel (GF/Ni) electrodeposited by $\mathrm{Ni}$ as alternative cathodes for microbial fuel cells, JTICE 89 (2018) 67-76.

[23] S. Hrapovic, M.F. Manuel, J.H.T. Luong, S.R. Guiot, B. Tartakovsky, Electrodeposition of nickel particles on a gas diffusion cathode for hydrogen production in a microbial electrolysis cell, Int J Hydrogen Energy 35 (2010) 7313-7320.

[24] I. Satar, M. Ghasemi, A.A. Saad, W.N.R.W. Isahak, W.R.W. Daud, M.A. Yarmo, Production of hydrogen by Enterobacter aerogenes in an immobilized cell reactor, Int J Hydrogen Energy 42 (14) (2016) 9024-9030.

[25] G.C. Gil, I. Chang, S, B.H. Kim, M. Kim, J.K. Jang, H.S. Park, H.J. Kim, Operational parameters affecting the performannce of a mediator-less microbial fuel cell, Biosens Bioelectron 18 (2003) 327-333.

[26] R.B. Gunn, P.F. Curran, Membrane potentials and ion permeability in a cation exchange membrane, Biophys J 11 (7) (1971) 559-571.
[27] P.A. Salembo, J.M. Perez, W.A. Lloyd, B.E. Logan, High hydrogen production from glycerol or glucose by electrohydrogenesis using microbial electrolysis cells, Int $\mathrm{J}$ Hydrogen Energy 34 (2009) 5373-5381.

[28] E. Marsili, J.B. Rollefson, D.B. Baron, R.M. Hozalski, D.R. Bond, Microbial biofilm voltammetry: Direct electrochemical characterization of catalytic electrode-attached biofilms, Appl Environ Microbiol 74 (23) (2008) 7329-7337.

[29] C.E. Reimers, C. Li, M.F. Graw, P.S. Schrader, M. Wolf, The identification of cable bacteria attached to the anode of a benthic microbial fuel cell: Evidence of long distance extracellular electron transport to electrodes, Front Microbiol 8 (2055) (2017) 1-14.

[30] S.S. Lim, E.H. Yu, W.R.W. Daud, B.H. Kim, K. Scott, Bioanode as a limiting factor to biocathode performance in microbial electrolysis cells, Bioresour Technol 238 (2017) 313-324.

[31] P.A. Salembo, M.D. Merrill, B.E. Logan, Hydrogen production with nickel powder cathode catalysts in microbial electrolysis cells, Int J Hydrogen Energy 35 (2010) $428-437$.

[32] A.Y. Yeng, www.mylinkedin.com/audreyyingyeng. Date accessed 10-10-2016, 2016.

[33] Alibaba, www.alibaba,com. Date accessed 12-6-2019, 2019.

[34] A A. Lasia, Electrochemical impedance spectroscopy and its applications, New York Heidelberg Dordrecht London, London, 2014.

[35] Z. He, F. Mansfeld, Exploring the use of electrochemical impedance spectroscopy (EIS) in microbial fuel cell studies, Energy Environ Sci 2 (2) (2009) 215-219.

[36] P. Vanysek, Introduction to electrochemical impedance, Department of Chemistry, University of Calgary, Canada, 1994.

[37] Z. Lu, P. Girguis, P. Liang, H. Shi, G. Huang, L. Cai, L. Zhang, Biological capacitance studies of anodes in microbial fuel cells using electrochemical impedance spectroscopy, Bioprocess Biosyst Eng 38 (2015) 1325-1333.

[38] X.M. Guo, E. Trably, E. Latrille, H. Carre're, J.P. Steyer, Hydrogen production from agricultural waste by dark fermentation: A review, Int J Hydrogen Energy 35 (2010) 10660-10673.

[39] A. Bisaillon, J. Turcot, P.C. Hallenbeck, The effect of nutrient limitation on hydrogen production by batch cultures of Escherichia coli, Int J Hydrogen Energy 31 (2006) 1504-1508.

[40] V.L. Cardoso, B.B. Romão, F.T.M. Silva, J.G. Santos, F.R.X. Batista, J.S. Ferreira, Hydrogen production by dark fermentation, Chem Eng Trans 38 (2014) 481-486.

[41] A. Ghimire, L. Frunzo, F. Pirozzi, E. Trably, R. Escudie, P.N.L. Lens, G. Esposito, A review on dark fermentative biohydrogen production from organic biomass: Process parameters and use of by-products, Appl Energ 144 (2015) 73-95.

[42] M.D. Merrill, B.E. Logan, Electrolyte effects on hydrogen evolution and solution resistance in microbial electrolysis cells, J Power Sources 191 (2009) 203-208.

[43] E.S. Ralph, Relationship between total alkalinity, conductivity, original pH, and buffer action of natural water, Ohio J Sci 60 (5) (1960) 303-308.

[44] S. Babanova, K. Carpenter, S. Phadke, S. Suzuki, S. Ishii, T. Phan, E. Grossi-Soyster, M. Flynn, J. Hogan, O. Bretschgera, The effect of membrane type on the performance of microbial electrosynthesis cells for methane production, $J$ Electrochem Soc 164 (3) (2017) 3015-3023.

[45] D.R. Lovley, The microbe electric: conversion of organic matter to elctricity, Curr Opin Biotechnol 19 (2008) 564-571.

[46] T. Chookaew, P. Prasertsan, Z.J. Ren, Two-stage conversion of crude glycerol to energy using dark fermentation linked with microbial fuel cell or microbial electrolysis cell, N Biotechnol 31 (1) (2014) 179-184.

[47] D.F. Call, B.E. Logan, Hydrogen production in a single chamber microbial electrolysis cell lacking a membrane, Environ Sci Technol 42 (9) (2008) 3401-3406.

[48] E. Lalaurette, S. Thammannagowda, A. Mohagheghi, P.C. Maness, B.E. Logan, Hydrogen production from cellulose in a two-stage process combining fermentation and electrohydrogenesis, Int J Hydrogen Energy 34 (2009) 6201-6210.

[49] T. Jafary, W.R.W. Daud, M. Ghasemi, M.H.A. Bakar, M. Sedighi, B.H. Kim, A.A. Carmona-Martínez, J.M. Jahim, M. Ismail, Clean hydrogen production in a full biologicalmicrobial electrolysis cell, Int J Hydrogen Energy xxx (2018) 1-8.

[50] Z. Yu, L. Peng, W. Xiao-bin, S. Yan-ping, Influence of initial biofilm growth on electrochemical behavior in dual-chambered mediator microbial fuel cell J Fuel Chem Technol 40 (8) (2012) 967-972.

[51] W.F. Bleam, Reduction-Oxidation Chemistry, Academic Press, SPi Global India, Soil and Environmental Chemistry, 2016, pp. 445-489.

[52] S. Kato, Microbial extracellular electron transfer and its relevance to iron corrosion, Microb Biotechnol 9 (2) (2016) 141-148.

[53] L.P. Bicelli, B. Bozzini, C. Mele, L. D'Urzo, A review of nanostructural aspects of metal electrodeposition, Int J Electrochem Sci 3 (2008) 356-408. 